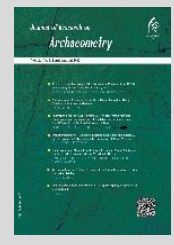

\title{
The Technical Study of Paper-support Textile Inscription of Mulla Ismail's Mosque in Yazd, IRAN
}

\author{
Parvin Soleimani $^{*}$, Tahereh Shishebori ${ }^{2}$ \\ ${ }^{1}$ Ph.D Student, Conservation of Historic Properties, Faculty of Conservation, Art University of Tehran, \\ IRAN \\ ${ }^{2} P h . D$ Student, Conservation of Historic Properties, Faculty of Conservation, Art University of Isfahan, \\ IRAN
}

\begin{abstract}
Quranic inscriptions are among the decorative elements commonly used in Islamic architecture. This is largely due to the fact that among the Islamic visual arts, calligraphy is the most related with holy Quran. Through calligraphy, the Holy Speech is represented before the viewers' eyes. In addition to immediate conveying of the holy message, the Islamic calligraphy meets, spiritually, an aesthetic function as well. Calligraphic inscriptions, containing various arts such as calligraphy, gilding as well as cover embellishment, comprise a major part of Persian artistic and historical works. In respect of historical studies, thus, Quranic inscriptions have always been on focus. In this connection, one of the major arts implemented onto fabric surfaces has been inscription the fabric support of which painted, mainly in water color, with geometric and floral patterns. Created in different eras with various techniques and materials, inscriptions are among the most important architectural decorations giving a special effect to historical buildings. Typically, the best examples of tile inscriptions can be found in the great mosque (or Masjid-e-Jami) as well as in the Shah Mosque (also known as Imam Mosque) of Isfahan. Similarly, among the brick and plaster inscriptions, those found in Lajeem Tower, Masjid-eJame Isfahan and in Peer Bakran Shrine respectively, are noteworthy. Also, the inscriptions used in the Red, Kabud, and Modavar Domes of Maraghe, represent a salient instance made of brick-and-tile fretwork. Meanwhile, w ooden inscriptions in Masjid-e-Jami of Abyane, Kashan are delicate ones. Fabric-made inscription of Masjid-e-Mulla Ismaeel, Yazd, implemented on a paper support, is one of the architectural decorations survived from Qajar era. Mullah Ismaeel Mosque was built by Akhound Mullah Ismaeel Aghdaie in Yazd, at the time of Fath-Ali Shah Qajar. The shrine of Mullah Ismaeel, placed in a room at the southern side of the mosque, is a structure with Qajar architectural features. At the three sides of the southern platform of the shrine, the Holy Quranic Verse of Jomo'a (Friday) has been inscribed in a horizontal rectangular frame in Sulus Jali calligraphic style, decorated with arabesque margins on the plaster support around the frame. The inscription in question lacks a specific date and therefore, it is very difficult to determine its date. How ever, the plaster-made inscription implemented at either sides of the fabric-made inscription, bears a date, dating back to Qajar era. This inscription, mounted on the wall, includes floral motifs as well as Quranic verses. The historical era was attributed to Qajar time considering the features of the stone inscription installed in the mosque entrance. In terms of scientific research, scant attention has been given to the mentioned inscription
\end{abstract}


and to similar works in Iran. In general, not many of such examples have survived the major part of which belongs to Safavid and Qajar era. Examination of such inscriptions, in terms of the kind of fabric used and colors and binders applied, can reveal important results helping to classify the various materials used in fabric-made inscriptions in different eras. Material identification of historical objects has a great importance for better understanding and reproduction process of ancient arts as a basic prior to applying the appropriate conservation method. Identification of materials such as paper, binder and pigments can help to distinguish a historical era and to have a better understanding of that era. For example, this can help to identify which techniques, or more importantly which materials, were used to apply a fabric-made inscription in Qajar era. A paper-based work, for instance, consists of other materials, other than paper itself, such as pigments, ink, binder, etc. Thus, it is first necessary to identify the chemical ingredients used in the work, as well as their interactions, based on the result of which, the most appropriate methods can be adopted and best materials applied in order to restore the work(s) in question. The present research mainly focused on identifying the materials used to make paper, binder and color applied in discussed inscriptions. The results, based on commonly used methods as well as instrumental techniques (such as FTIR and SEM-EDS) indicated that the binder and the support used were mainly composed of carbohydrates. Also, the fabric used was made of cotton and the paper of pulp (obtained from worn out clothes). The pigments applied were organic and the painting technique was watercolor. To implement the inscription, in practice, the artist first would stick the fabric onto a paper support. Then, to draw the desired lines onto the fabric surface, the fabric was burnished. Finally, the inscription was painted and mounted on the wall.

Keywords: Inscription, Mulla Ismail's Mosque, FTIR, SEM-EDS, Spot Tests. 


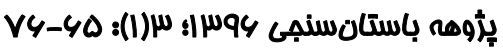

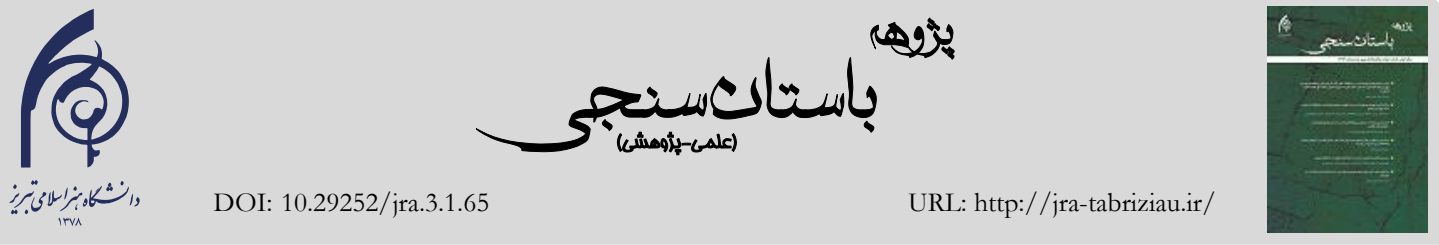

دقالم بِرَهوشى

\section{شناسايى مواد بوم يارجه با تكيه كاه كاغذى مسجد ملا اسماعيل

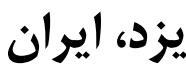

\section{يروين سليمانى "، طاهره شيشلهبرى}

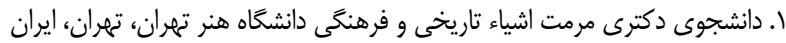

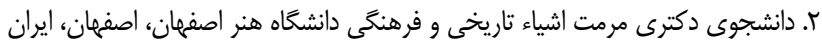

كتيبه ازجمله مهمترين عناصر تزئينات وابسته به معمارى محسوب مىشـود كـه در بـازههـاى زمـانى بـا روشهــاى متعـدد و مصـالح

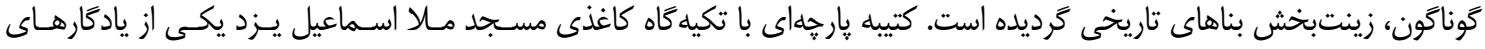

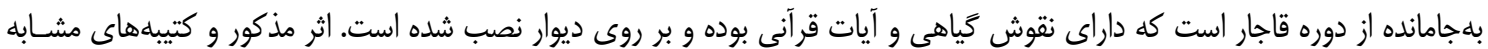

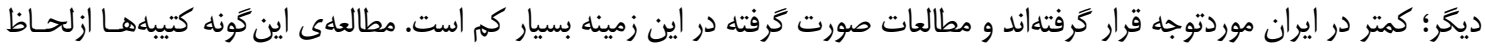

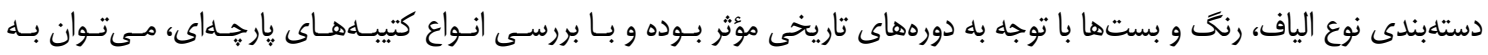
دستابندى طيفى از مواد تشكيلدهنده انواع كتيبههاى يارجهاى در دورههاى مختلف دست يافت. هدف اصلى اين تحقيق بررسى نـوع

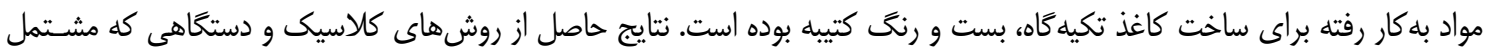

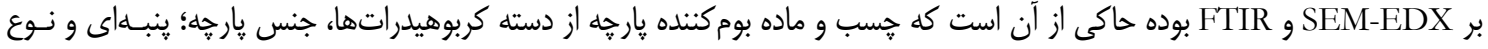

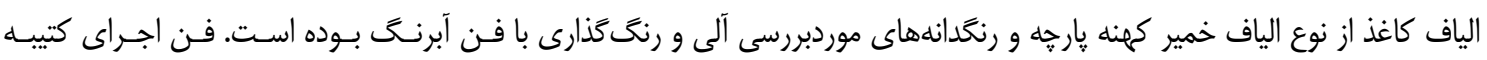

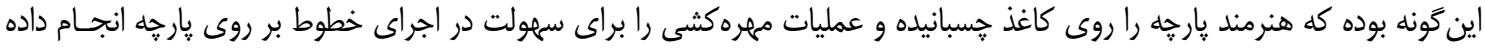

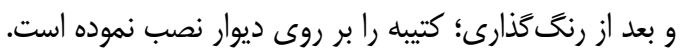

وازَّان كليدى: كتيبه، مسجد ملااسماعيل، SEM-EDX، FTIR، شيمى كلاسيك.

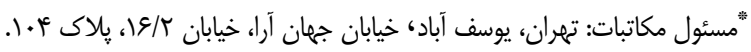
يست الكترونيكى: soleimani.parvin@yahoo.com

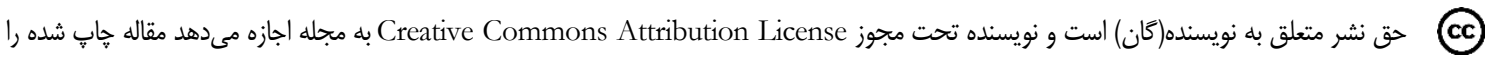

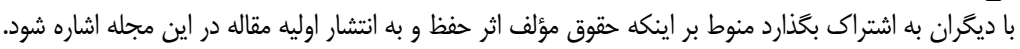


يك كتيبه پارجهاى، از خه شيوههايى و مهمتر از آن از خه

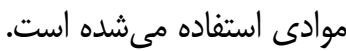

\section{r. ي ييشينه تحقيق}

مسجد ملااسماعيل توسط آخوند ملااسـماعيل عقــايى در

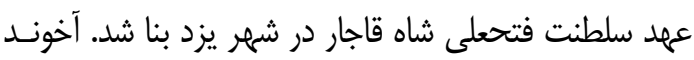

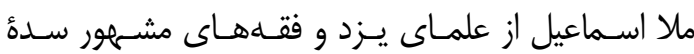

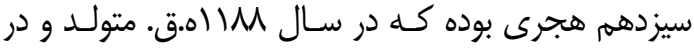

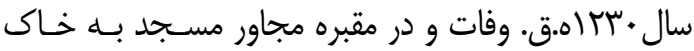

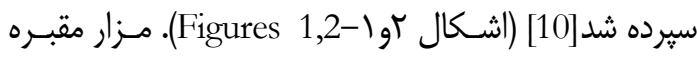
ملا اسماعيل كه اتاقى در ضلع جنوبى مسجد ملإسماعيل

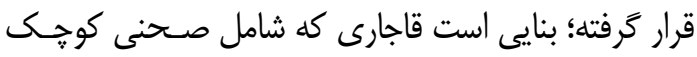

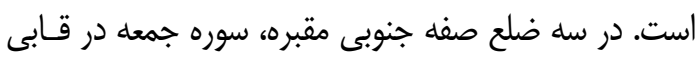
مستطيل شكل و بلهصورت افقى با قلم ثلث جلى ونى و تزئينات

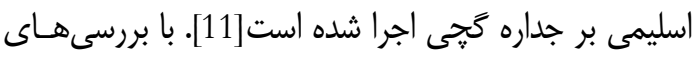

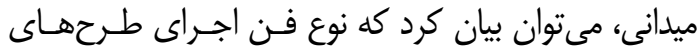

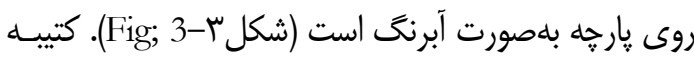

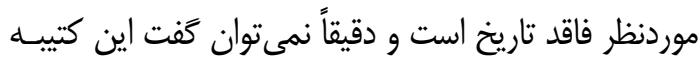

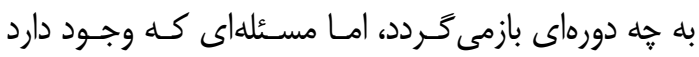

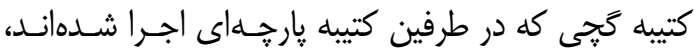

داراى تاريخ است كه به دوره قاجار مربوط مىشود.

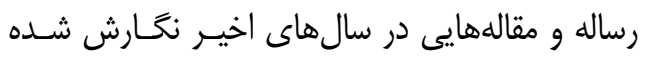

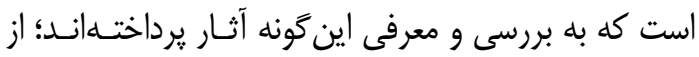
نمونههاى كاربرد نقاشى آبرنگ بر روى يار خها، مى توان به

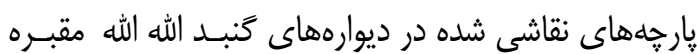

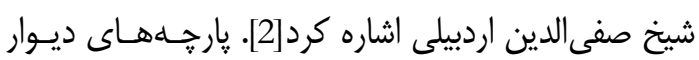

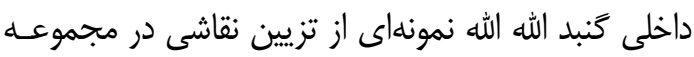
شيخ صفى الدين است. كتيبه زير كنبد بعد از اجرا بر سطح

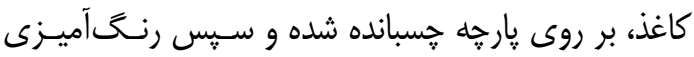

انجام يافته و در خاتمه بر سطح ديوار تثبيت شده است.

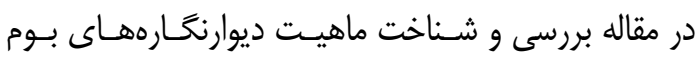

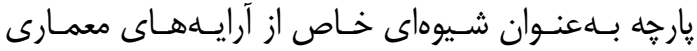
اسلامى ايران، نغارنده به معرفى و بررسى شـيوه اجـراى

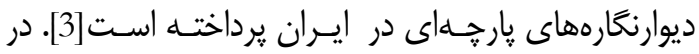

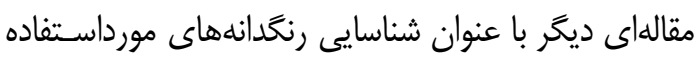
در تزئين كتيبه كاغذى خانه انصارين تبريز، به شناسايى دئ داني

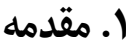

كتيبهاى قرآنى از تزئينات'رايج در بناهاى اسلامى است، جراكه هنر خطاطى، در ميان هنرهاى تجسمى اسلامى از همه بيشتر به قرآن وابسته است. اين هنر كلام وحى ران ادر

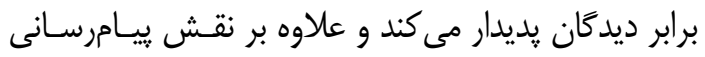

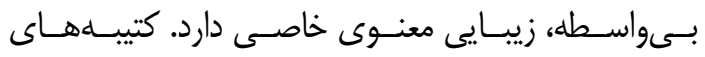

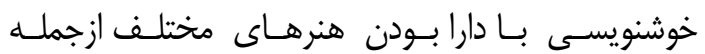
خوشنويسى، تذهيب و در برخى موارد تجليد، بخش مهمى

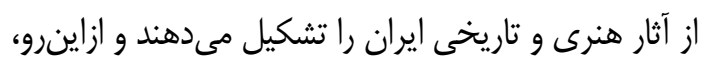

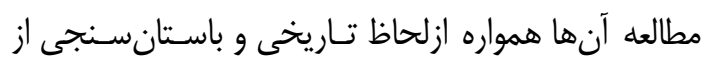

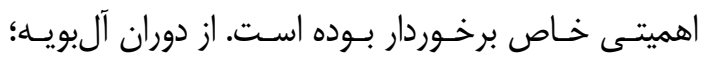
خطاطى كم كم در كار طراحى و تزيينـات بـه كـار ترفتـه شد[1]. بافت يارجههاى دوره سلجوقى و استفاده از خطوط

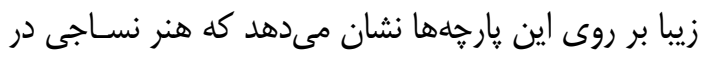
اين عصر به حد كمال رسيده است. از مهمترين تزئينـاتى كه بر روى يارجه انجام مى گيرد، يته است. در تزيين يتـه؛ يارجه، بستر و عامل اتصال به سطح ديوارهى بنا بوده، كـهـ

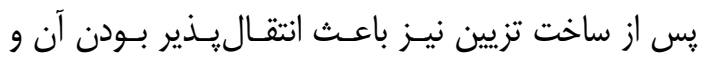

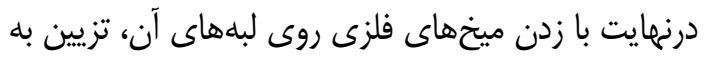
ديواره بنا نصب مىشده اسـت. يكى از هنرهـاى مهـهم و و

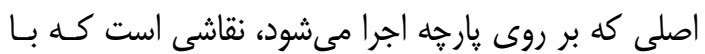

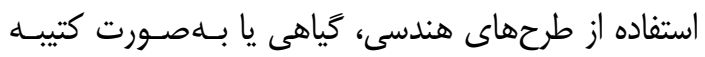

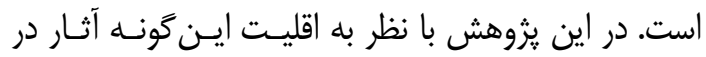

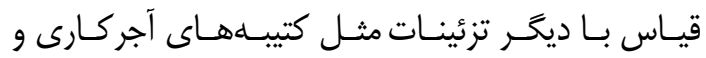

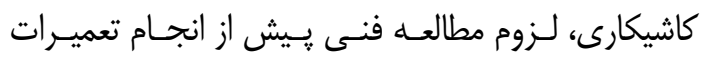

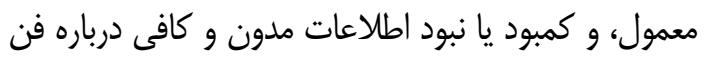
اجراى كتيبه يارجهاى مسجد ملا اسماعيل يزد مورد توجه

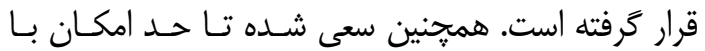
بهرهمندى از روشهاى علمسى اطلاعساتى دربـارهٔ مـوادو و

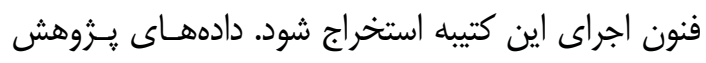

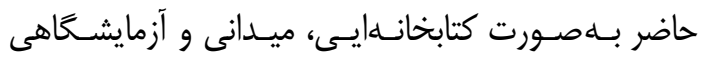

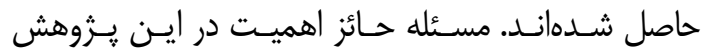

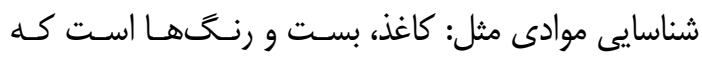

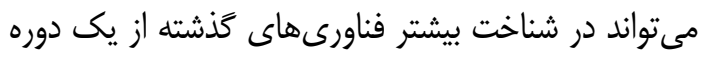

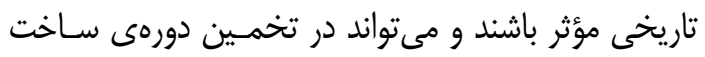

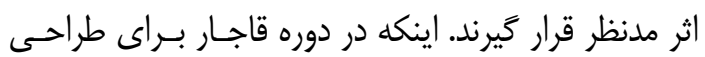




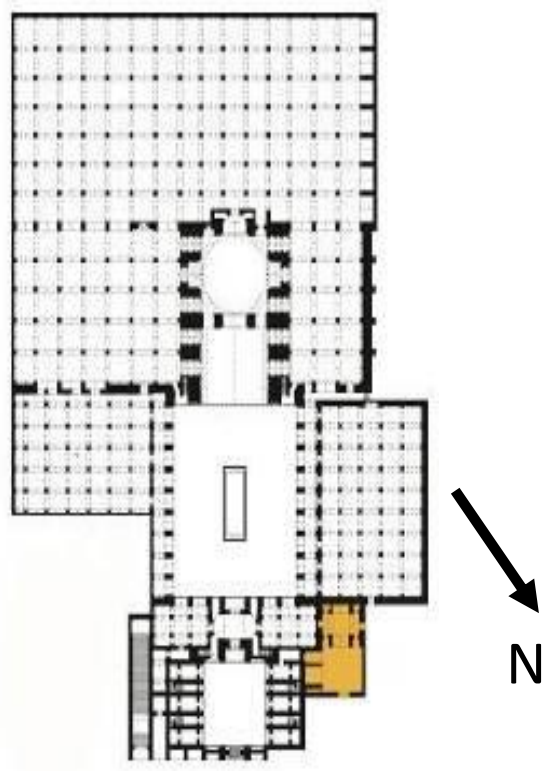

شكل (: يلان مسجد ملااسماعيل و محل قرارگيرى كتيبه پار خهاى (منبع: اداره ميراث فرهنخى يزد)

Fig; 1: Mullah Ismail Mosque Plan and Textile inscription (Source: Yazd Cultural Heritage Office)

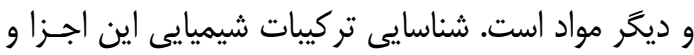

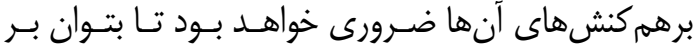

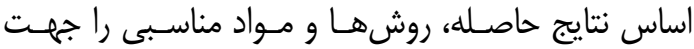

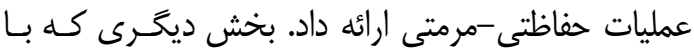

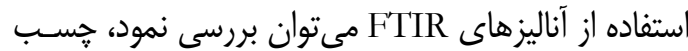

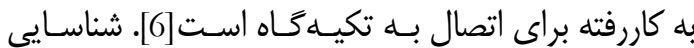

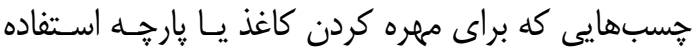

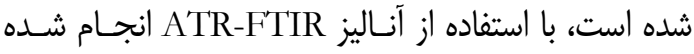

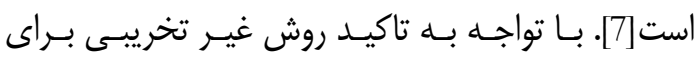

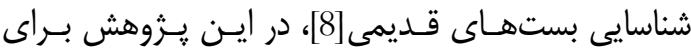

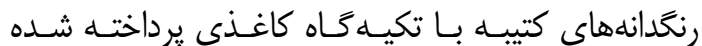

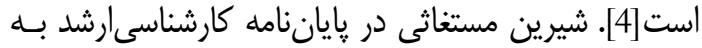
بررسى كتيبهى كاغذى مـوزه هنرهاى تزيينسى اصفيهان

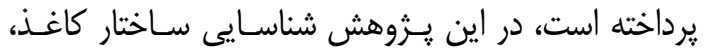

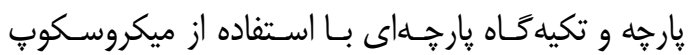

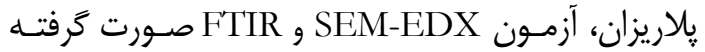

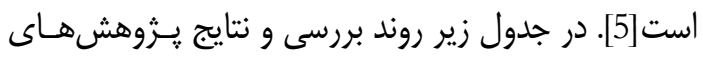

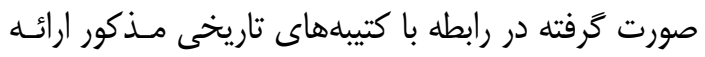
شده است (جدول (-Table 1).

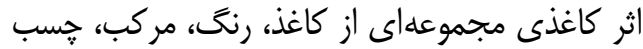

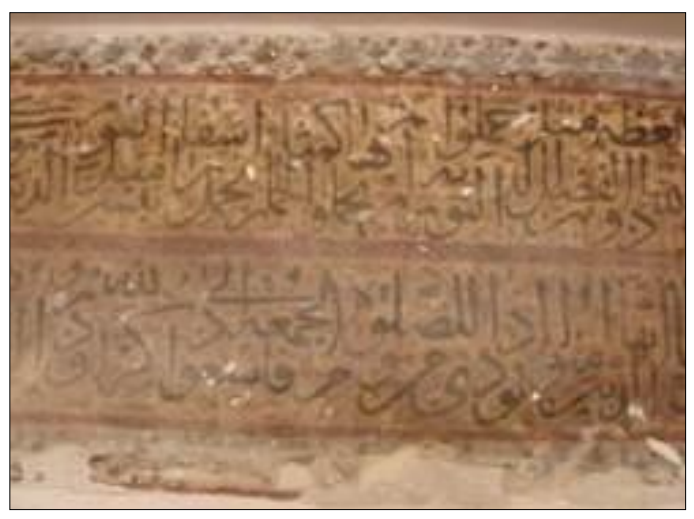

شكل": كتيبه دستويس، ابعاد متفاوت حروف مشابه مثل: الف Fig; 3: Handwritten inscription, different aspects of the الف same letters, such as the letter

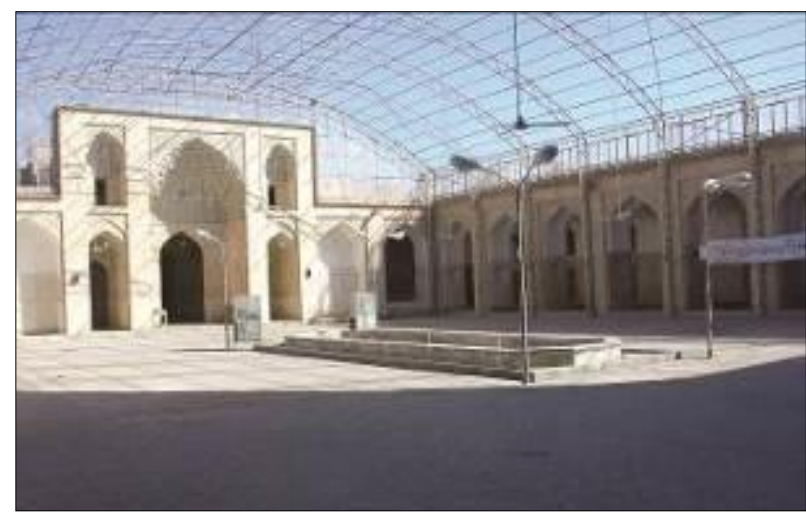

شكل ז: نماى داخلى مسجد ملااسماعيل يزد

Fig; 2: interior view of Mulla Ismail mosque 
جدول (: معرفى مواد كتيبههاى كاغذى و پيارجهاى

Table1: Introduction of paper and textile inscriptions

\begin{tabular}{|c|c|c|c|}
\hline $\begin{array}{c}\text { نتايج } \\
\text { Results }\end{array}$ & $\begin{array}{c}\text { تجزيه دستخاهى } \\
\text { Instrumental Analysis }\end{array}$ & $\begin{array}{c}\text { شيمى كلاسيك } \\
\text { Classic Chemistry }\end{array}$ & $\begin{array}{c}\text { نمونها } \\
\text { Samples }\end{array}$ \\
\hline $\begin{array}{c}\text { رنحدانه آبى؛ لاجورد } \\
\text { Blue pigment; Azure } \\
\text { Rَخدانه قرمز؛ سرنج } \\
\text { Red Pigment; Red Lead }\end{array}$ & $\begin{array}{c}\text { نور یالاريزان } \\
\text { Polarized light }\end{array}$ & 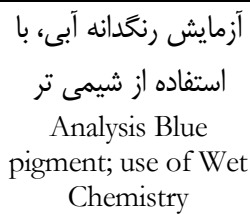 & $\begin{array}{c}\text { كتيبه كاغذى خانه } \\
\text { خارين تبريز[4] } \\
\text { The paper-based } \\
\text { inscription in Tabriz } \\
\text { Home 's Ansarin }\end{array}$ \\
\hline 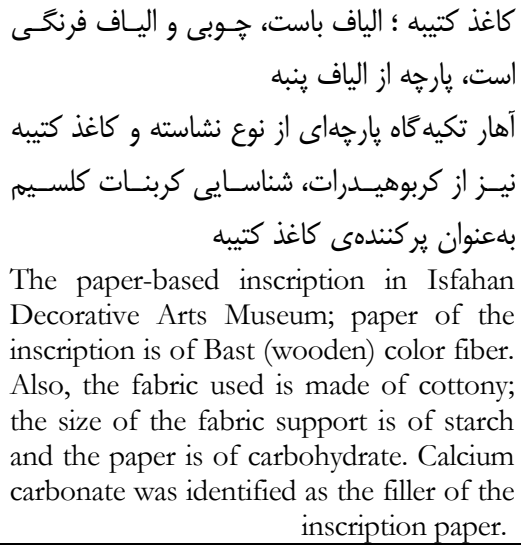 & 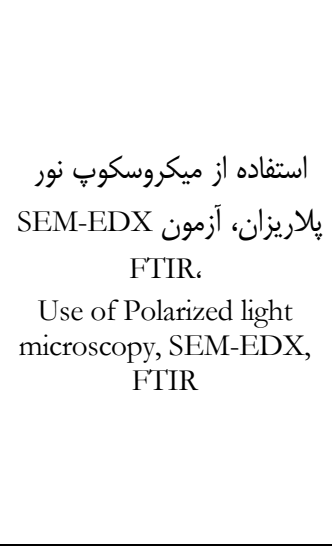 & $\begin{array}{l}\text { آزمونهاى نقطهاى } \\
\text { Spot test }\end{array}$ & 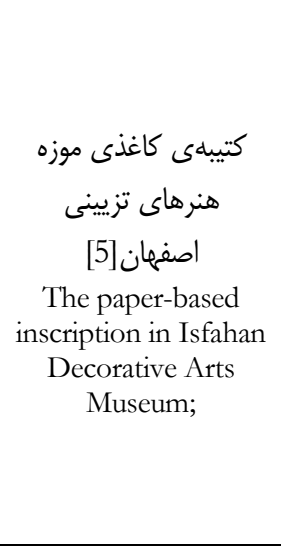 \\
\hline 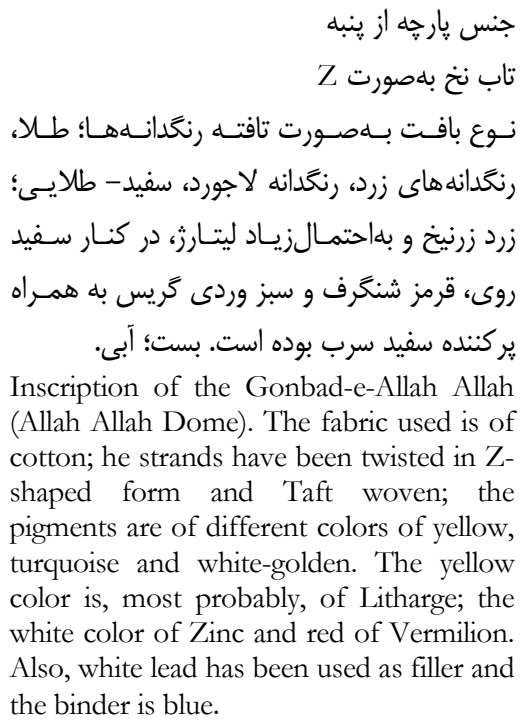 & $\begin{array}{l}\text { FTIR, SEM-EDX آزمون } \\
\text { Use of SEM-EDX, FTIR }\end{array}$ & 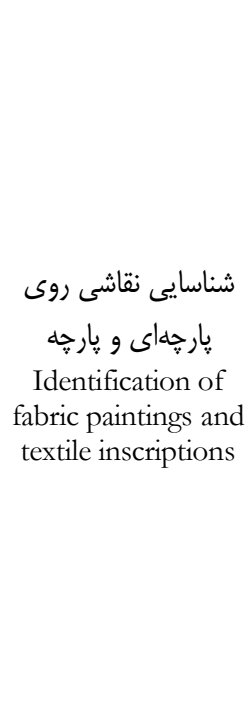 & 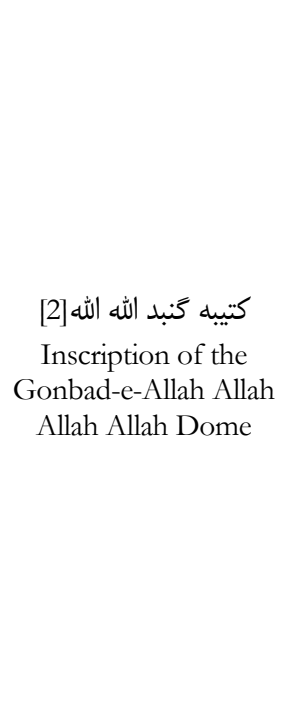 \\
\hline
\end{tabular}

بررسى علمى نقاشىها، يار خهها، نسخ و اسناد تزئين شده

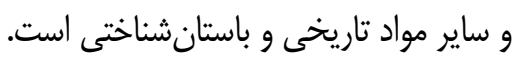

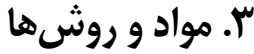
ب- (1. مواد و دستخًاههاى مورداستفاده

قدم اول براى شناسايى تعدد لايـهـهـاى كتيبـه مـوردنظر،

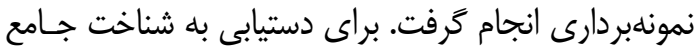

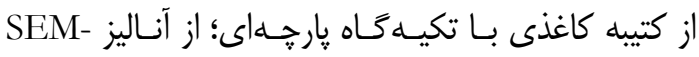

$$
\begin{aligned}
& \text { شناسايى نوع بستها از روش طيـفسـنجى مـادونقرمـز }
\end{aligned}
$$

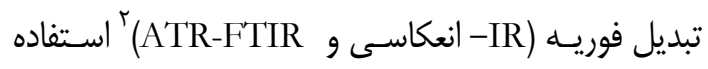

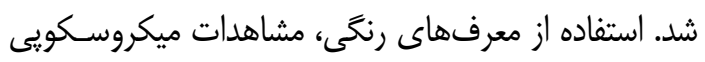

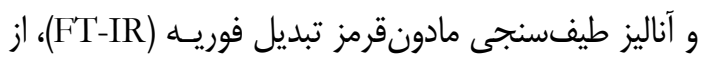

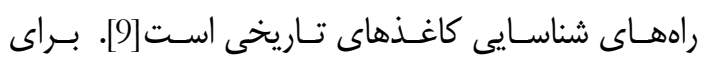

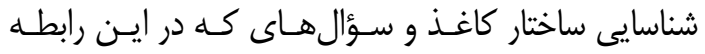

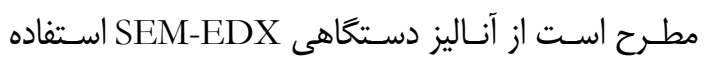

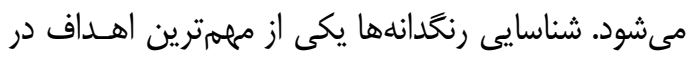




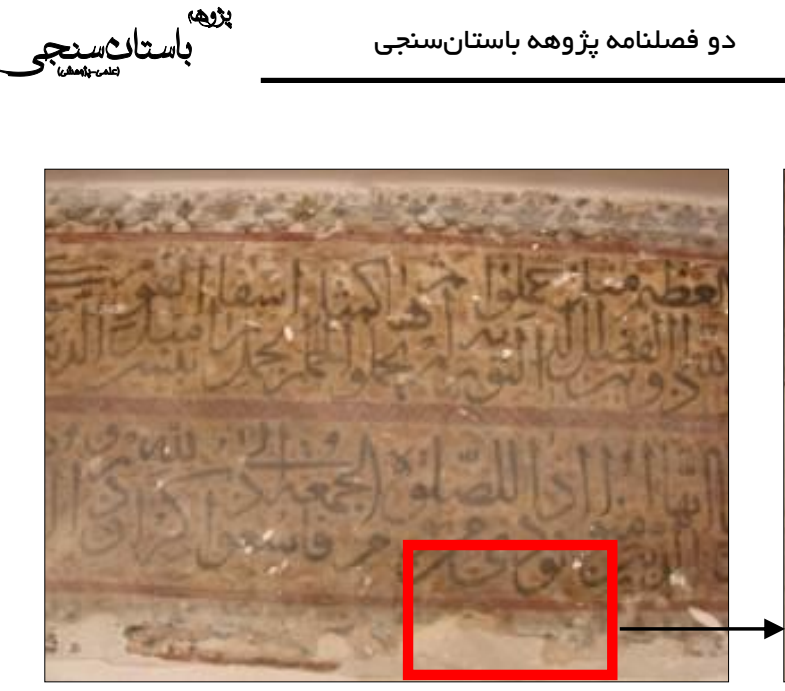

شكل أ: محل نمونهبردارى از كتيبه يارجهاى

Fig; 4: textile inscription of sampling place

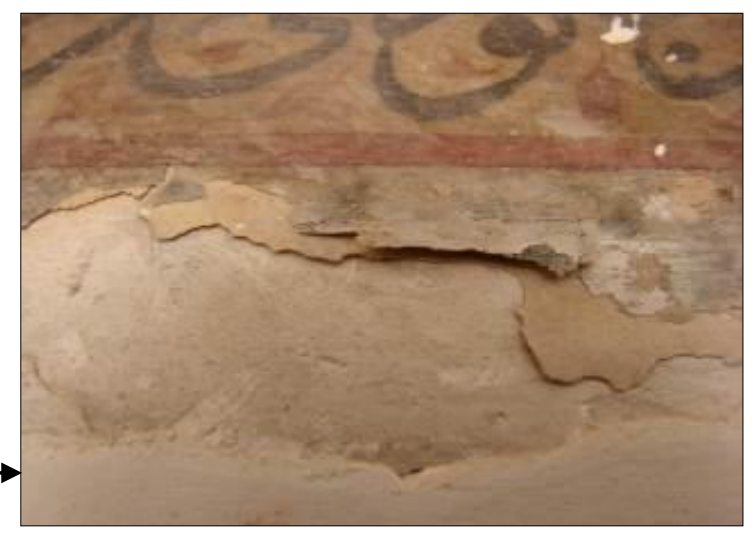

شكل ه: محل نمونهبردارى از كتيبه يارجهاى

Fig; 5: textile inscription of sampling place

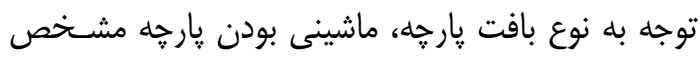

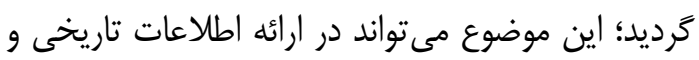

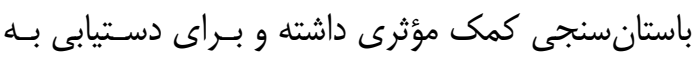

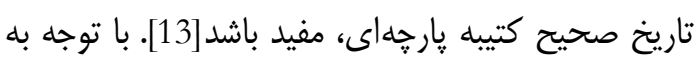

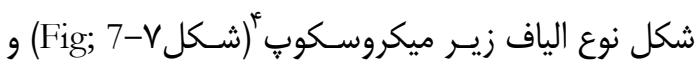

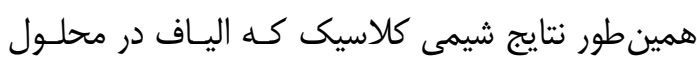
سود و استون نامحلول بود، مىتوان بيان كرد كه اليـاف

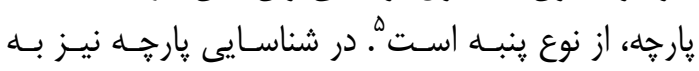

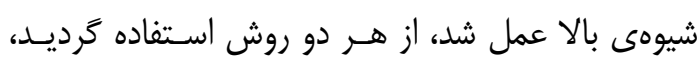

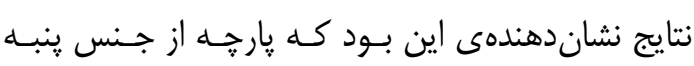

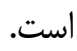

\section{ه. شناسايى الياف كاغذ با آناليزهاى دستخاهى

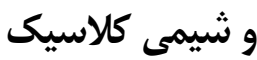

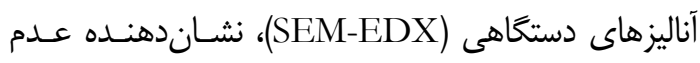
وجود ير كنندهايى از قبيل سفيد سرب [2]، كربنات كلسيم

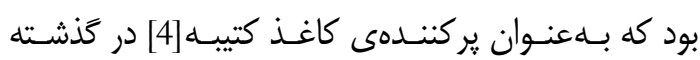

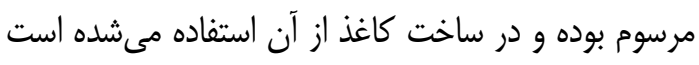

(مصاحبه شخصى با عباس عابد اصفهانى، (9 (1).

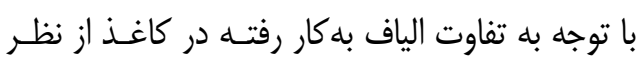

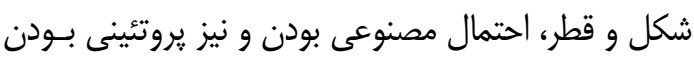

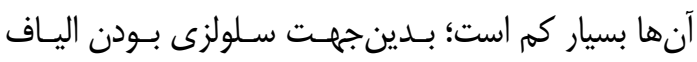

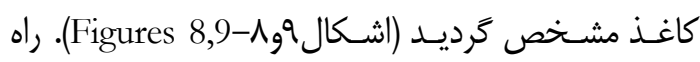

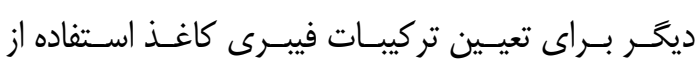

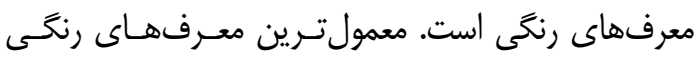

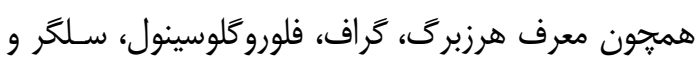

EDX با مشخصات Dino-Lite سـاخت كشـور تـايوان، مالو S/ N: 9C2399، P/ N: Am413T-VW متالورزى رازى براى شناسايى الياف كاغذ، بررسى كـاربرد

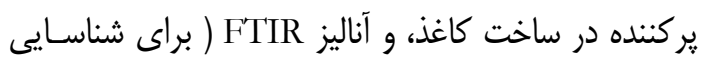

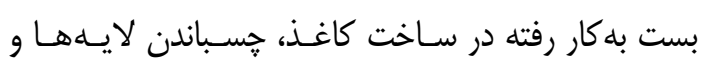

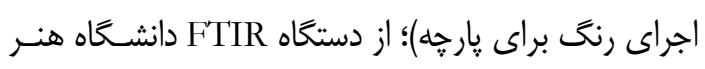

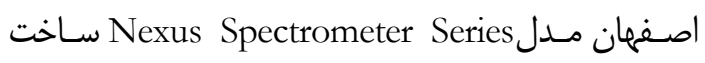
كشور آمريكا استفاده شد. براى شناسايى نوع الياف يارجـهـ

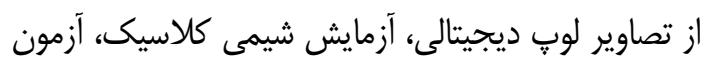

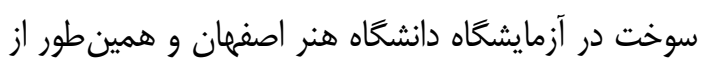
تصاوير SEM استفاده شد.

\section{س-r. نمونهبردارى}

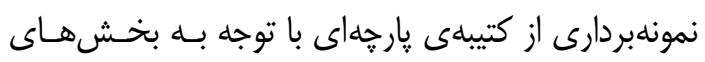

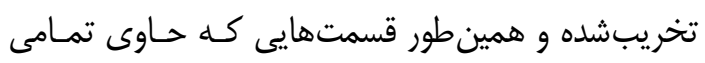

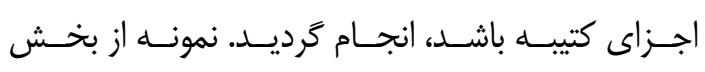

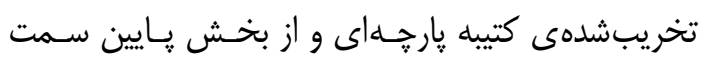

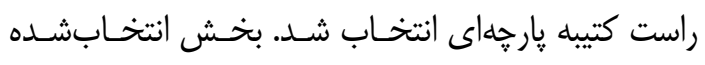

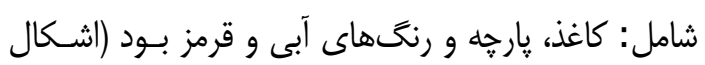

.(Figures 4,5- $\left.\omega_{g}\right)^{f}$

\section{f أ. شناسايیى يارجه}

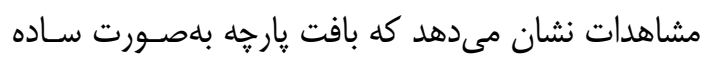
(Plain Weave)

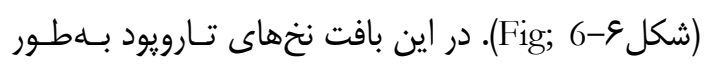

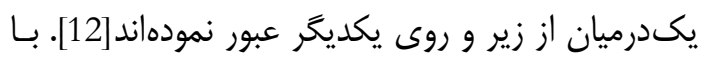

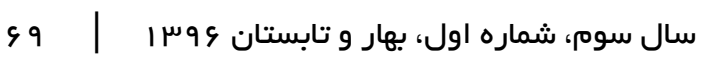




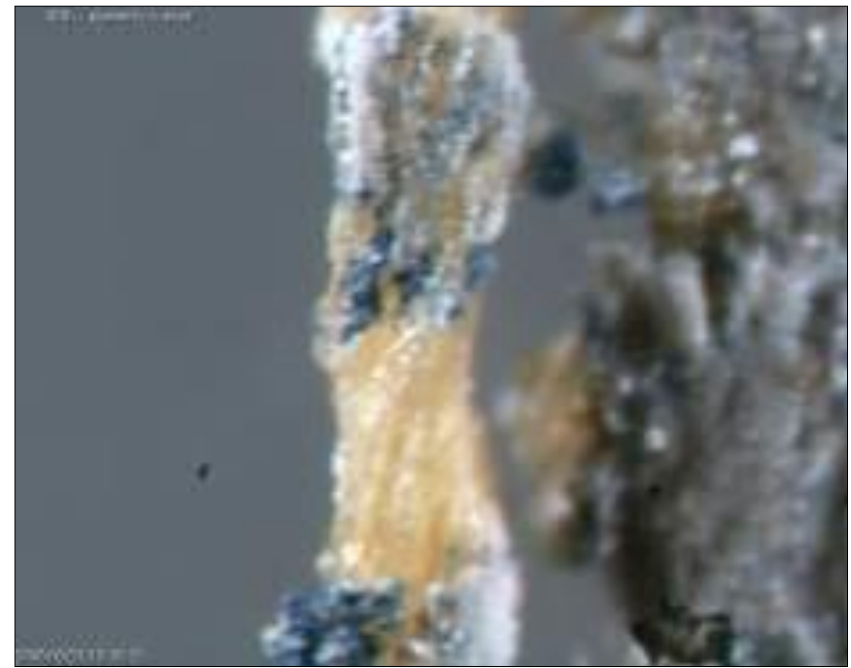

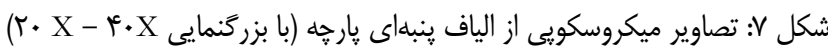
[13]

Fig; 7: Microscopic images of cotton yarn of textile (40X-20X)

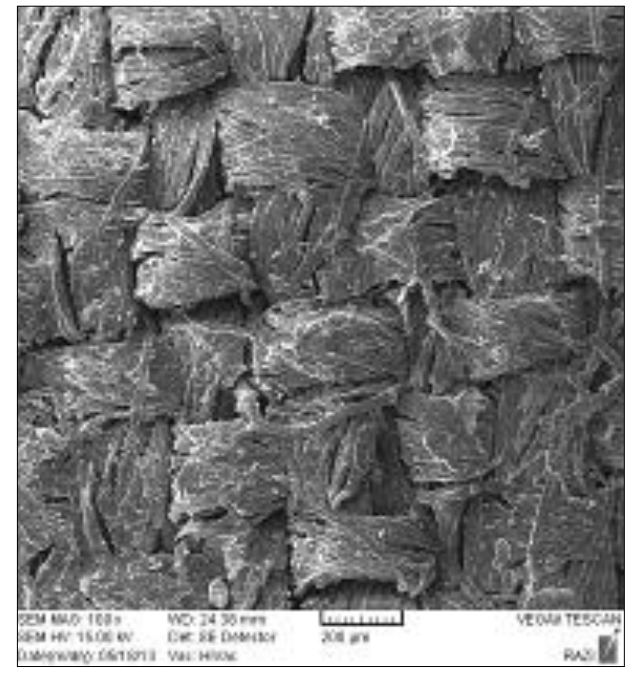

شكل צ· بافت ساده و متمركز الياف پارجه (شناسايى با آناليز

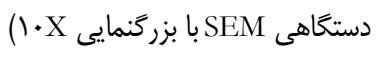

Fig; 6: Simple texture and Focused textile yarn (identification by analysis SEM-10x)
براى ساخت كاغذ كه در كذشته مرسوم بود؛ استفاده شــه

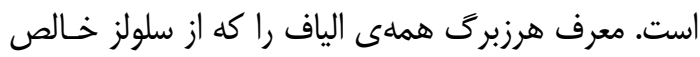

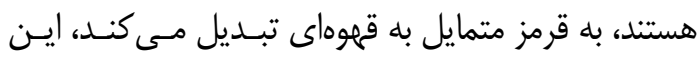

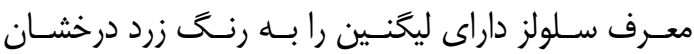

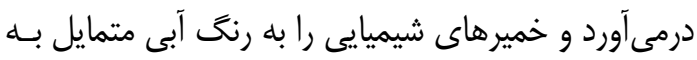

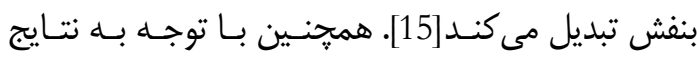

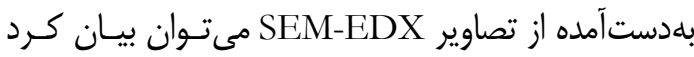
كه كاغذ مورداستفاده از الياف سـلولزى بــه همـراه اليـاف خمير كهنه پيار خه است.

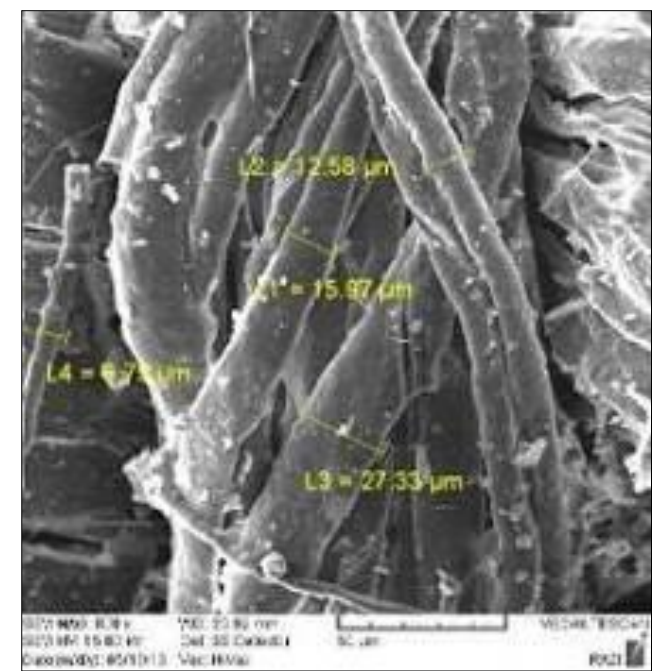

شكلج: تصوير SEM از الياف كاغذ با بزركنمايى ..1 برابر Fig; 9: SEM of paper-800X
يديد پِتاسيم (Isenberg H, 1967, 225-228-237) است

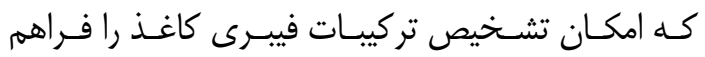

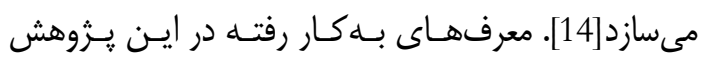
معرف هرزبرگ، كراف C و سلكَر اسـت. شناسـايى اليـاف

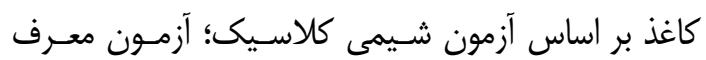

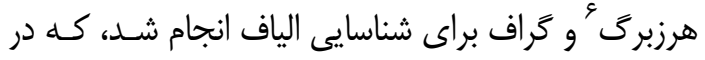

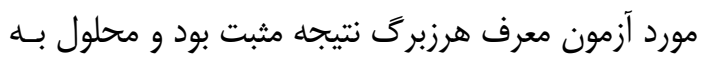

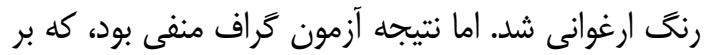

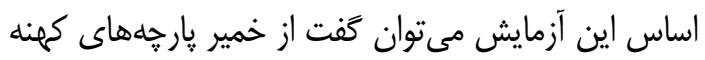

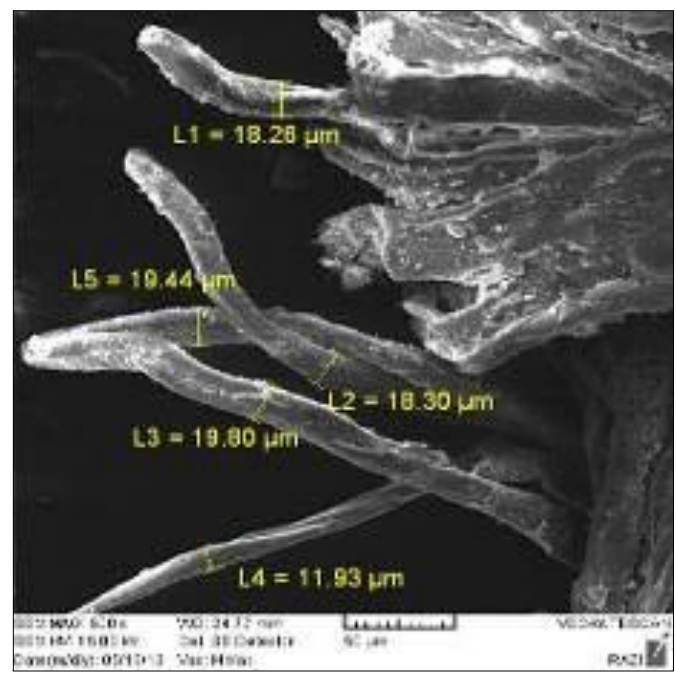

شكلم : تصوير SEM از الياف كاغذ با بزركنمايى ..1 برابر Fig; 8: SEM of paper-800X

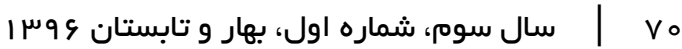




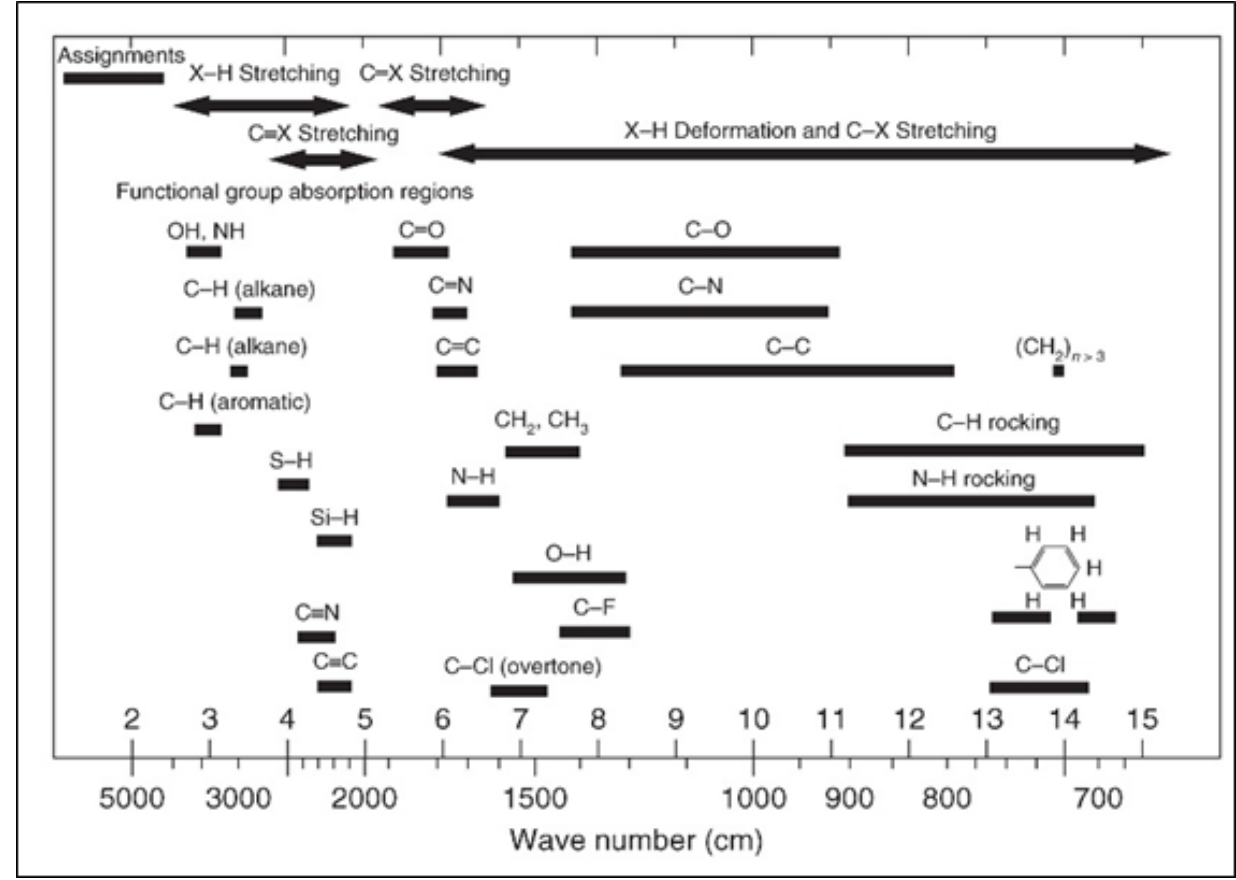

شكل • (: محل گروههاى عاملى تركيبات آلى در طيف جذبى FTIR

Fig; 10: The location of functional groups of organic compounds in the absorption spectrum FTIR

كربونيل در حسدود • IVD جـذب دارد و C-H كششى در

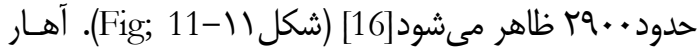

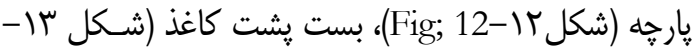
Fig; 13

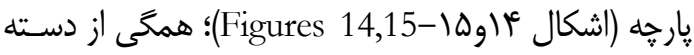
كربوهيدراتها هستند.

\section{و. شناسايیى نوع آهار كاغذ و بست}

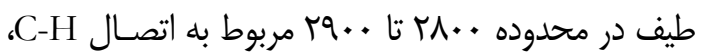

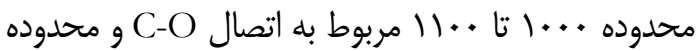

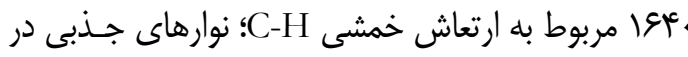

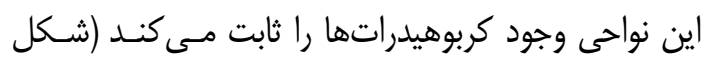
• (Fig; 10). براى نمونه در مـورد صـمغ عربسى؛ گـروه

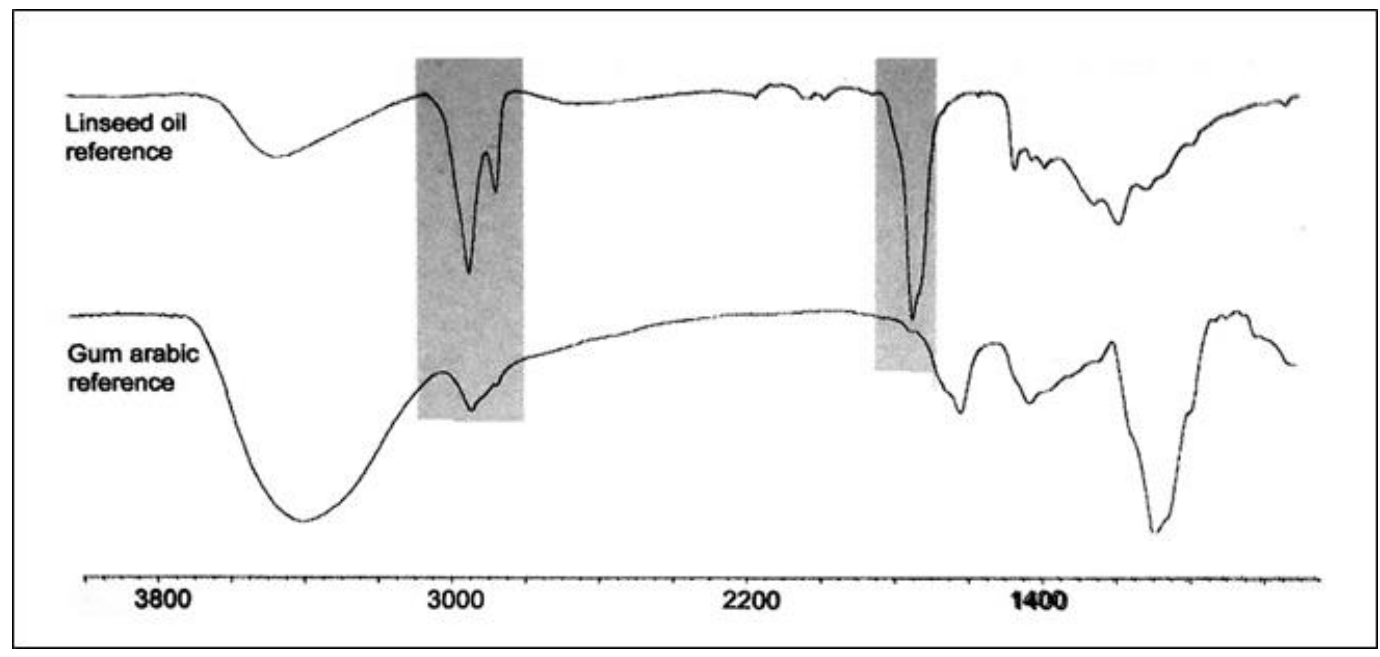

شكل (ا: محل گروههاى عاملى تركيبات آلى، روش طيف سنجى FTIR ؛ نمونه موردى صمغ عربى[16]

Fig; 11: the location of functional groups of organic compounds, FTIR Spectroscopy method; Case Study, Gum Arabic 


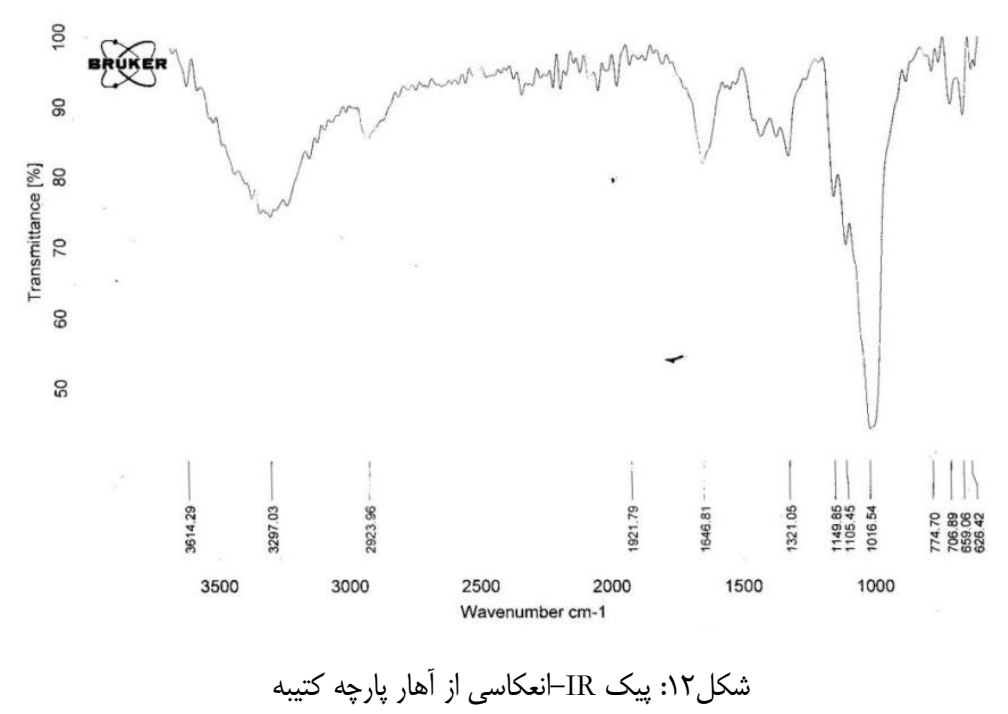

Fig; 12: FT-IR-spectrum of the inscription glue textile

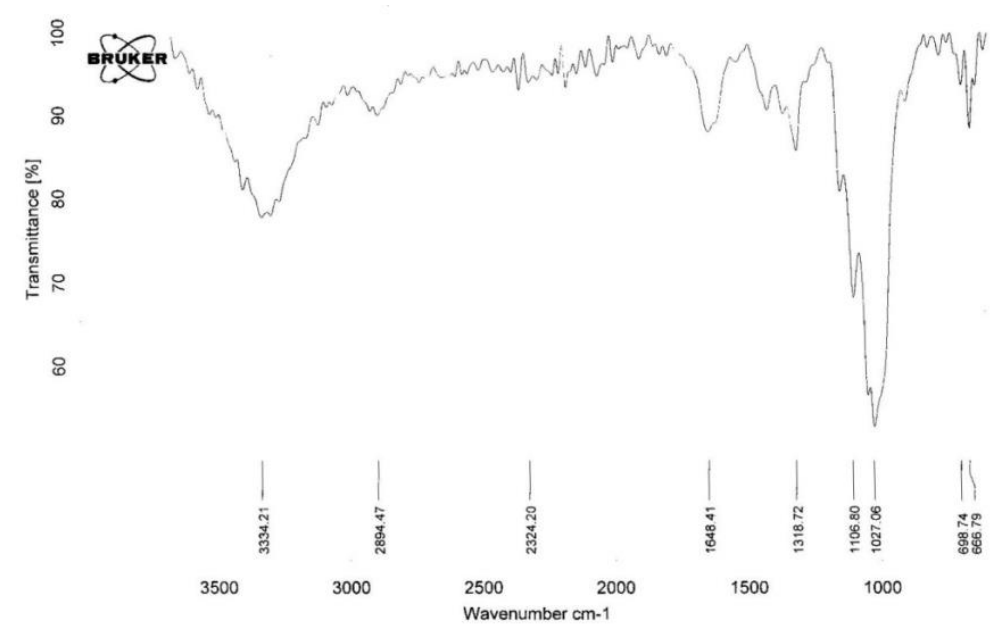

شكل זו: ييك IR- انعكاسى از بست קֶت كاغذ

Fig; 13: FT-IR-spectrum of the glue behind the paper

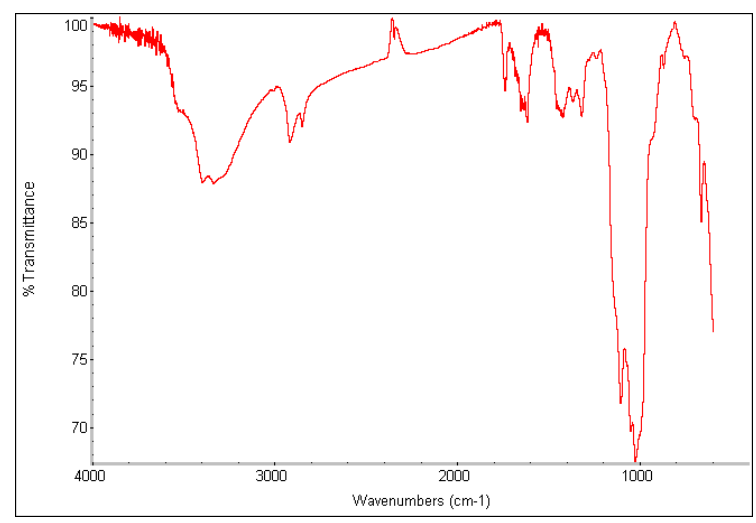

شكل ها: بيك ATR-FTIR بست به كار رفته براى رنخها

Fig; 15: ATR-FTIR spectrum of the glue used to color

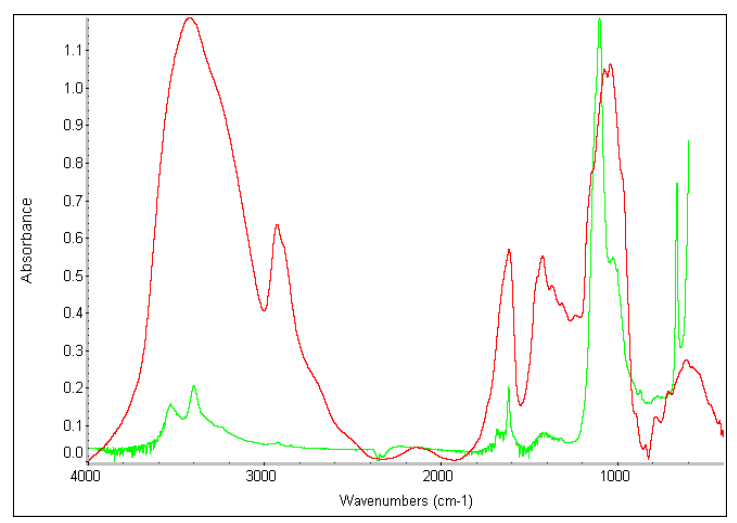

شكل (ا: ييك ATR-FTIR بست به كار رفته براى رنخها؛ بررسى يبيى بست صمغ عربى (به عنوان شاهد) و نمونه مطالعاتى

Fig; 14: ATR-FTIR spectrum of the Glue used to color; study of witness glue and case of study sample

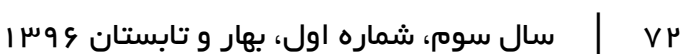




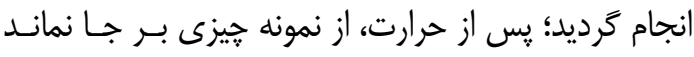

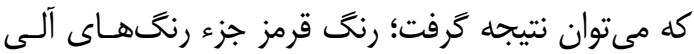
است. دو رنحى روناس و قرمز دانه از خذشته كاربرد داشـته

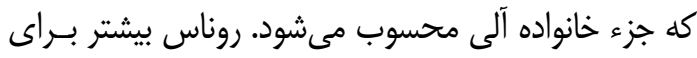

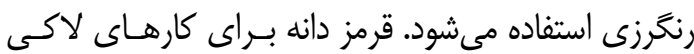

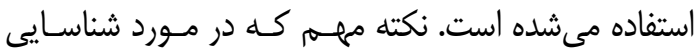
مواد و مصالح وجود دارد، تغيير ساختار است؛ تغيير سـاختار

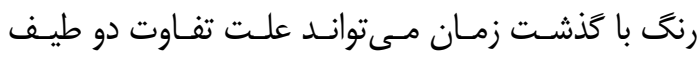

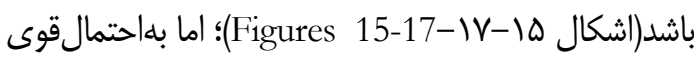
براى رنخ قرمز؛ از قرمز دانه اسـتفاده شـــه اسـت [13]. از

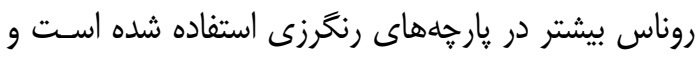

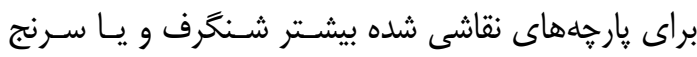

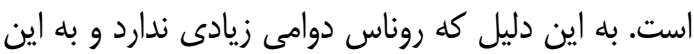
دليل در رنخرزى استفاده مىشود به اين دليل است كه در

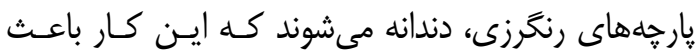
تثبيت شدن روناس مى شود(مصـاحبه شخصى بـا بـا حميــا ملكيان. كار كاه حفاظت و مرمت كتابخانه مجلس شـوراى

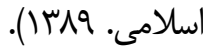

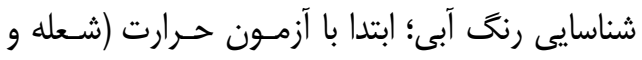

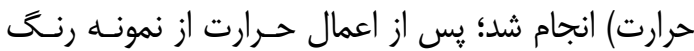

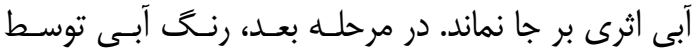

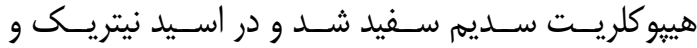

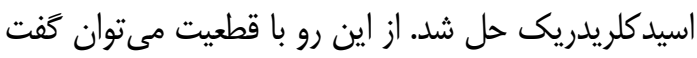

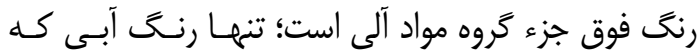
توسط محلول هييو كلريت سديم سفيد مى كردد، آبى نيـل

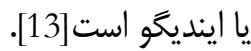

צ- (. معرفى بست و آهارهاى كربوهيدراتى

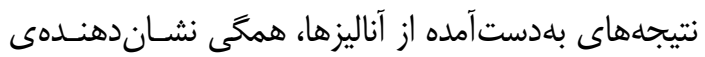
بستهاى كربوهيدراتها هستند كه خانوادهاى گستردهاى

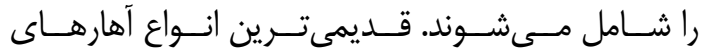

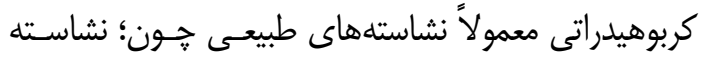

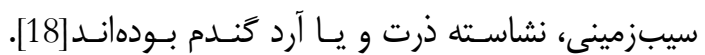

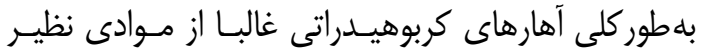

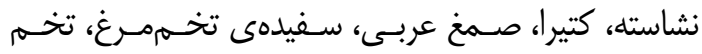
كل ختمى و صمغهاى كياهى ديخر، همرجنين از شيرابههـا

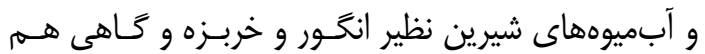

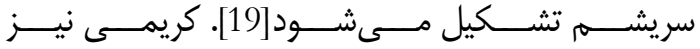
بستهاى كربوهيدراتى را شامل؛ صـمغ عربـ، سـريش، صمغ درختى، كتيرا و انزروت معرفى مىنمايد[8]. بست يا آهار در اثر موردمطالعـه، در ايـن خــروه قـرار

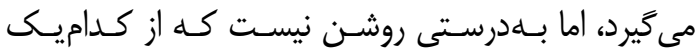

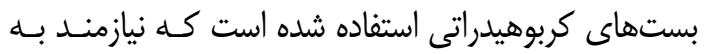

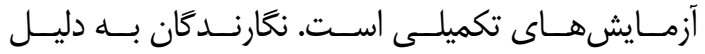
FTIR محدوديتهاى زمانى و نمونهبردارى، فقط به آنـاليز

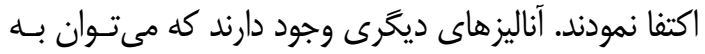
طيفسنجى ميكرو رامان[8] اشاره نمـود. انـواع روشهــاى كروماتوكر افى از مرسومترين فنون شناسايى بست هستـتند.

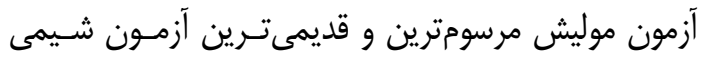
كلاسيك براى شناسايى بستهاى كربوهيدراتى است[11]].

V. اسناسايى رنخَهاى كتيبه شناسايى رنغ قرمز؛ ابتدا آزمون حـرارت (شعله و كـوره)

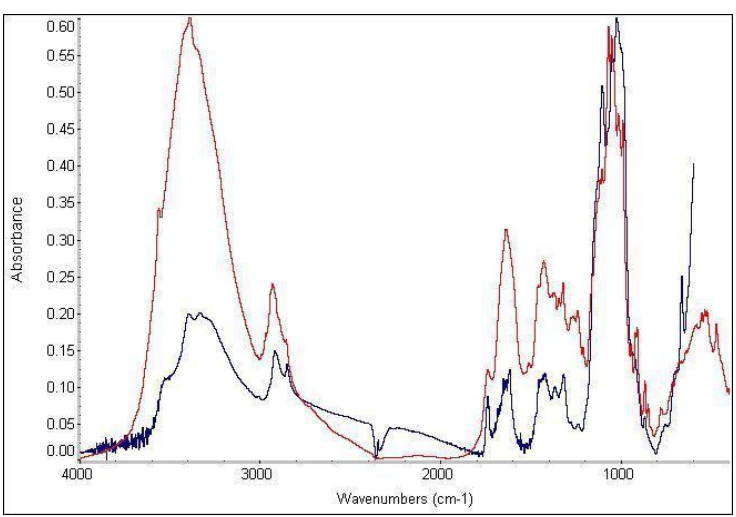

شكلVا: مقايسه نتايج FTIR روناس (نمونه و شاهد) Fig; 17: compare FTIR results (sample and witness)

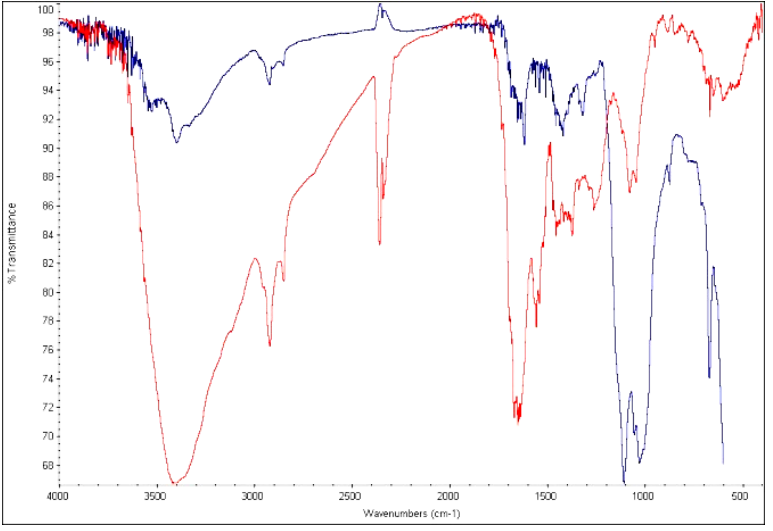

شكل \& (: مقايسه نتايج FTIR قرمز دانه (شاهد و نمونه)

Fig; 16: compare FTIR results kermes (sample and witness) 


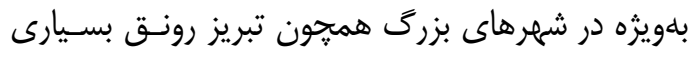
داشته و آثار متعددى از اين شيوه بلهجاى مانده اسـت كـهـ

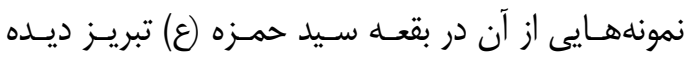
مىشود[4]. ז. انعكاسى يعنى نمونه را بدون يـودر كـردن مسـتقيماً در

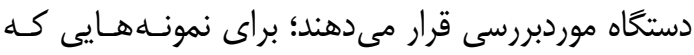

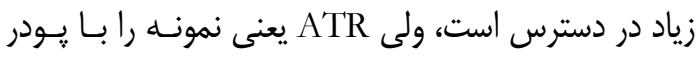
KBr قرص تهيه مىشود.

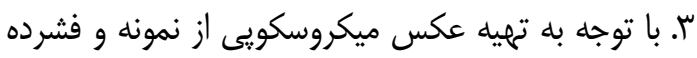

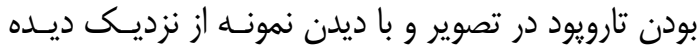

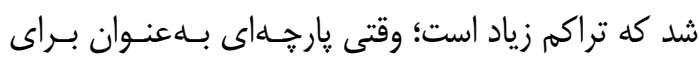

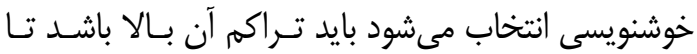
قلهمو بر روى آن بهراحتى حركت كند.

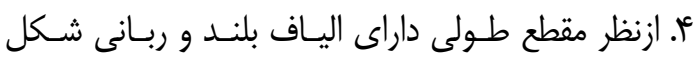
همراه بيِيششهايى در فواصلى از طول ليف و ازنظر مقطع عرضى لوبيايى شكل است.

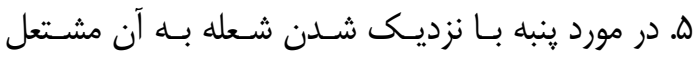

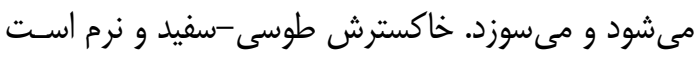

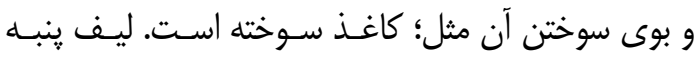

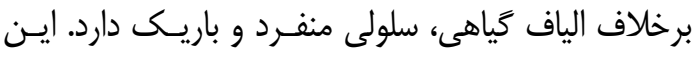

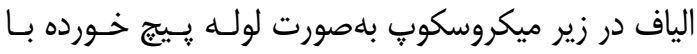

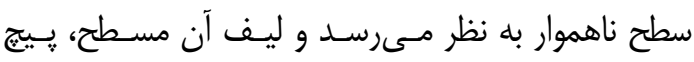
خورده، نامنظم و نوار مانند است.

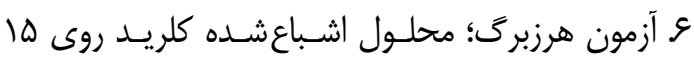

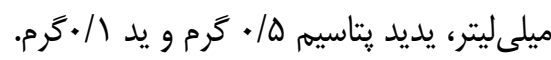

\section{Refrences}

[1] Zaki Mohammad H. Iranian industrial history (after Islam). Translated by Khalili M.A. Tehran: Eghbal; 1984.[in Persian] [زكى محمد حسن. تاريخ صنايع ايــان (بعـد از اسـلام). ترجمه خليلى محمدعلى. تهران: انتشارات اقبال؛ سوعا.

[2] Hajiani S, Madahi Ghivi M. Recognition of fabric paintings on the Allah Allah dome of Sheikh Safi-o-din Ardabili's tomb [Unpublished]; 2011. [in Persian] ] حاجيانى شيوا، مداحى گيوى مهدى. بررسى نقاشىهـاى

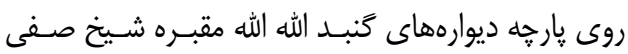

$$
\text { الدين اردبيلى [منتشر نشده]؛ • •وسו.] }
$$

\section{1. نتيجه كيرى}

كتيبههاى خطى به دليل اهميت خوشنويسى در ايـران بـــــ

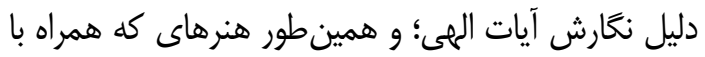

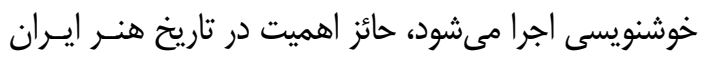

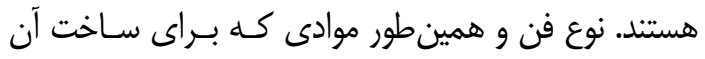

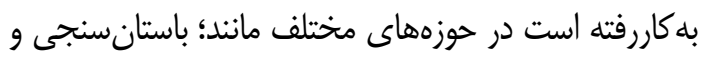

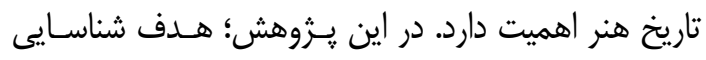

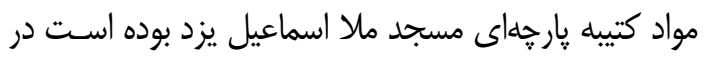

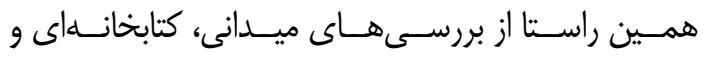

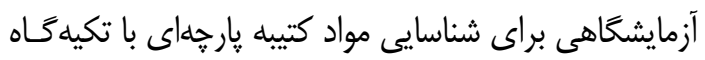

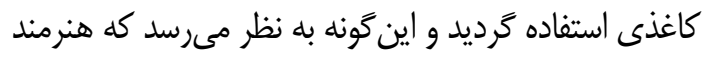

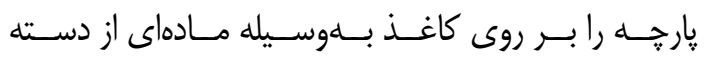

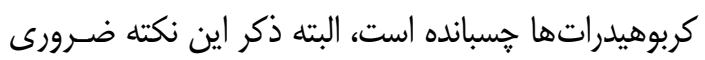

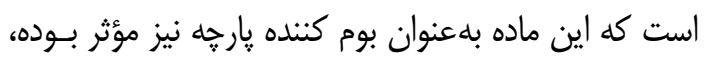

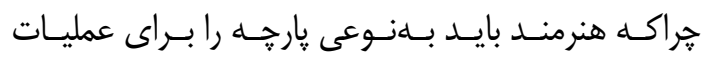

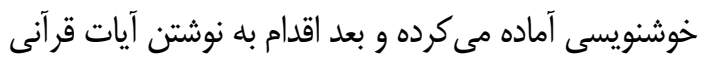

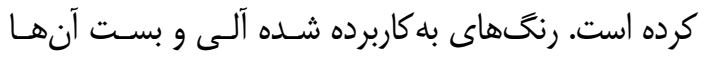

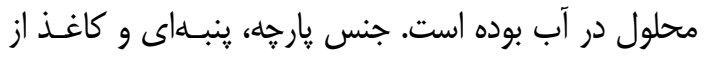
الياف خمير كهنه پارجه ساخته شده است. براى كسب نتايج

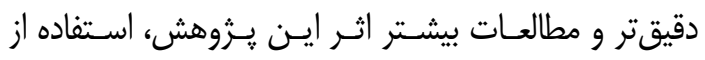

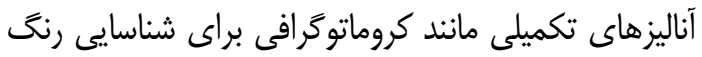
قرمز و نيز براى شناخت دقيق نوع بستها الزامى است.

\section{يـىنوشت}

ا. كتيبه مذكور بر روى كاغذ و بر تكيه كاهى از مقوا ايجاد شده است. ساخت كتيبهها بــه ايـن شـيوه در دوره قاجـار

[3] Hamzavi Y, Vatandoust R, Ahmadi H. An investigation and identify of essence of marouflaged canvasmural as a specific style of islamic architectural decoration in Iran. Journal of Reasearch Islamic Architecture 2017;4(13):130-48. [in Persian]

$$
\begin{aligned}
& \text { ] حمزوى ياسـر، وطـن دوسـت ياسـر، احمــى حسـين. }
\end{aligned}
$$

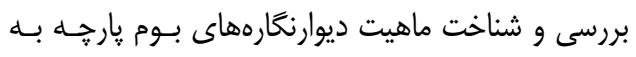

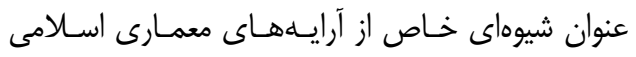

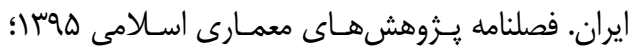

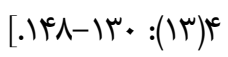


[4] Koochakzaei A, Nemati Babayloui A, Daneshpoor L. Identification of pigments used in decoration of paper inscription related to ansarin house of Tabriz. Color Science and Technology 2015;9:297-306. [in Persian]

$$
\begin{aligned}
& \text { [كوجكزايى عليرضا، نعمتى بابـايلو علىى، دانشـيور لـيلا. }
\end{aligned}
$$

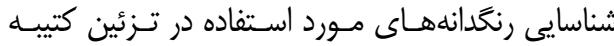

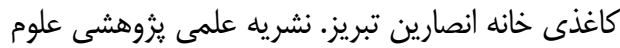

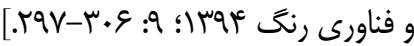

[5] Mostaghasi S. Technological, pathology and presenting the paper inscriptions for conservation and restoration plan to the year 1322 with textile support [Unpublished M.A Thesis]. Art University of Isfahan; 2017. [in Persian]

[مستغاثى شيرين. فنشناسى، آسـيبشناسى و ارايـهـى ]

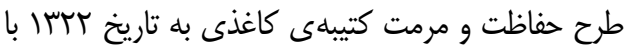

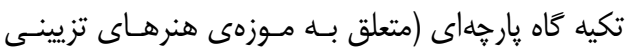

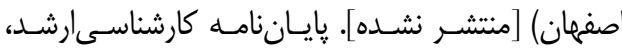

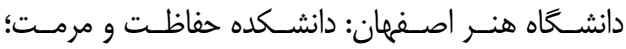

[.

[6] Seyyedahmadi M, Samanian K. Examining the techniques used in a large format photograph of Ahmad Shah Qajar using device analysis. Journal Management System 2016;25(3):96-113. [in Persian]

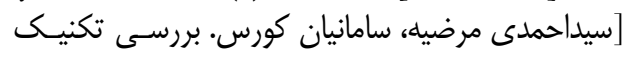

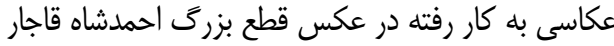

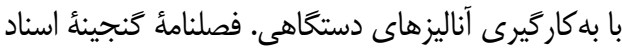

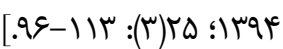

[7] Mahgoub H, Bardon T, Lichtblau D, Fearn T, Strlič M. Material properties of Islamic paper. Herit Sci 2016;4:34. doi:https://doi.org/10.1186/s40494-0160103-4.

[8] Karimy A, Holakooei P. Micro-Raman spectroscopy for non-invasive characterization of binding medium used in persian painting. Maremat \& Memari-eIran 2014;4(8):19-46. [in Persian]

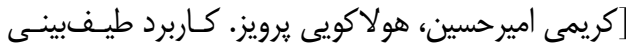

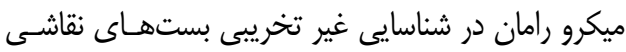

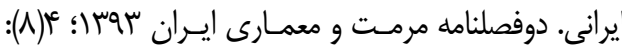
$[.98-19$

[9] B-Kasiri M, Younesi B, Yajam A. Identify historical paper fibers to dating feasibility of unknown samples. Journal of Research on Archaeometry 2016;2(1):29-38. [in Persian]
] باقرزاده كثيــى مسعود، يونسى بهـاره، يـاجم افسـانه.

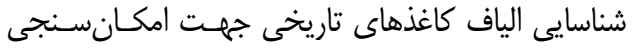

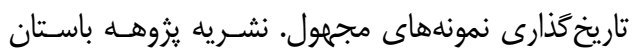

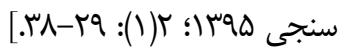

[10] Khadem zadeh MH. Historical mosques of Yazd city. Tehran: Cultural Heritage Base of Historical Yazd City; 2005. [in Persian]

]خادم زاده محمــد حسـن. مسـاجد تـاريخى شـهر يـزد.

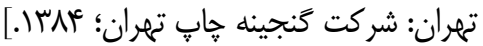

[11] Shishebori T. Conservation \& restoration of the western side section of plaster inscription of Mulla Ismail's tomb in Yazd [Unpublished B.A Thesis]. Art University of Isfahan, 2008. [in Persian]

[شيشهبرى طاهره. حفاظت و مرمـت بخشسى از كتيبـه كَجى ضلع غربى مقبره ملا اسماعيل يزد [متنشر نشـانده].

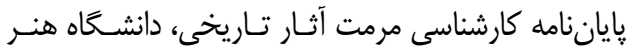

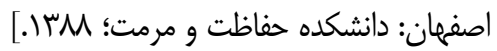

[12] Talebpour F, Ayatollah M. Principals of fabric analysis. Tehran: Al-Zahra University Press; 2003. [in Persian]

[طالب يور فريده، آيت اللهى مينو. اصول تجزيه يارجهـ و طرحهاى رنكى. تهران: انتشارات دانشخاه الزهرا؛ برئا.

[13] Soleimani P, Shishebori T. The fabric inscription of the tomb of Mullah ismaiel: An Archeological Study. The 2nd national conference on archaeology in Iran, Mashhad: 2015; 1-18. [in Persian]

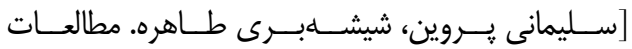

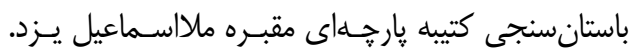
دومين همايش ملى باستانشناسى ايران عاجس|: (1-1).

[14] Hosseini someah M, Azadi Boyaghchy M, Pourtahmasi K. A review of the properties of fibers of the Seljuk and Timurid papers using instrumental techniques for identifying their fibers. Honar-ha-ye-Ziba 2017;22:67-76. [in Persian]

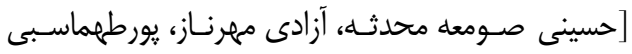
كامبيز. مرورى بر توصيف ويزگى اليـاف كاغـذهاى دوره

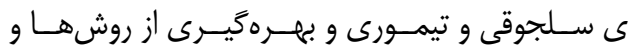

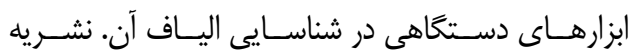

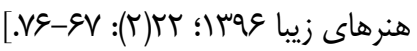

[15] Lienardy A. Manuel for paper conservation, maintenance and restoration. Translated by Sarvghad Moghadam Abollhassan. Mashhad: Islamic Research foundation; 2000. [in Persian] 


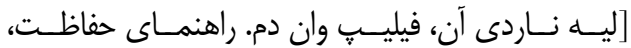

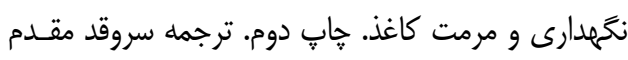

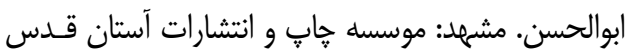

رضوى؛

[16] Karimy A, Vatankhah G. Review the methods glue Analysis in pigment. In: Razani M, Ajorlo B eds. Articles of the first and second national conferences on the application of scientific analysis Archaeometry \& restoration of cultural heritage. Tabriz: Tabriz Islamic Art University; 2012;165-208. [in Persian]

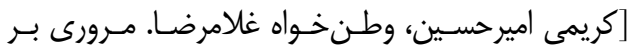

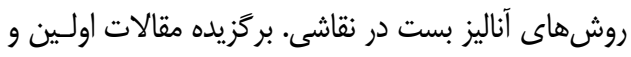

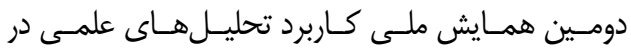

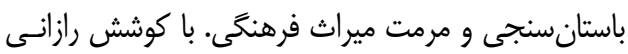

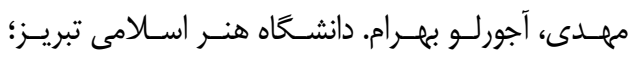

$[. r \cdot \Lambda-1 \% q]: 190$
[17] Stuart BH. Analytical techniques in materials conservation. John Wiley \& Sons; 2007.

[18] Saghafi M javad, Deh Pahlavan M, Zarineh H. Comparative and laboratory study of the Parthian-Sassanid textile fragment, from Moghadam museum of University of Tehran. Honar-Ha-Ye-Ziba 2011;45:35-43. [in Persian]

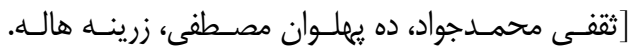

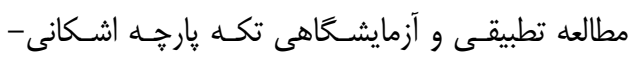

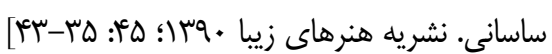

[19] Roohi Azizi M, Vatandoust A, Malekian

H. Tradition paper Restoration in Iran. Journal of Management System 2016;25(3):114-27. [in Persian]

[روحى عزيزى مزده، وطندوست رسول، ملكيان حميـد.

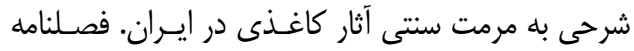

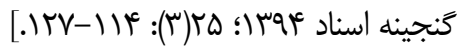

